\title{
Workplace resources, mentorship, and burnout in early career physician-scientists: a cross sectional study in Japan
}

Chithra R. Perumalswami', Shinichi Takenoshita ${ }^{2}$, Ayumi Tanabe ${ }^{3}$, Ranka Kanda ${ }^{4}$, Haruko Hiraike ${ }^{4}$, Hiroko Okinaga ${ }^{5}$, Reshma Jagsi ${ }^{1,6}$ and Kyoko Nomura ${ }^{2,7^{*}}$ (1)

\begin{abstract}
Background: Physician-scientists are a vital segment of the healthcare workforce, but they may face significant challenges balancing and integrating clinical responsibilities, scientific research, and domestic responsibilities. This study investigates factors associated with burnout among highly successful early career physician-researchers in Japan.

Method: Among 1790 physician awardees of Grant-in-Aid for Young Scientists by the Japanese Ministry in 2014-2015, 490 participated in this cross-sectional survey in 2016 (usable response rate 23.8\%). The primary outcome was psychological burnout, measured by the Copenhagen Burnout Inventory (i.e., personal burnout, work-related burnout, and patient-related burnout). "Workplace resources" in our study refers to the presence of career education in the workplace, promotion of gender equity, well-being consultation services on "career and work," "research," "harassment," and/or "mental health," as well as the presence of a role model in the workplace who has perceived good work-life balance.

Results: Among 408 physician-researchers (75\% male, mean age 37 yrs), personal burnout scores were slightly higher in women than in men (mean score, 41.9 points vs. 36.7 points, difference, 5.2, 95\% confidence interval, 0.5-9.9, $p=$ 0.029), but work-related and patient-related burnout scores did not differ significantly between genders. Over half of women $(64 \%)$ and men $(58 \%)$ had a mentor $(p=0.374)$. In multivariable general linear regression models, personal burnout scores were higher for women $(\beta=4.98, p=0.045)$, and lower among those who had a mentor $(\beta=-5.82$, $p=0.010)$ and whose workplaces had well-being consultation services $(\beta=-0.79, p=0.022)$. Work-related burnout scores were lower among those with larger amounts of grant funding $(\beta=-4.70, p=0.013)$, a mentor $(\beta=-6.12, p=$ 0.002 ), well-being consultation services $(\beta=-0.78, p=0.008$ ) and a role model with a perceived good work-life balance $(\beta=-4.00, p=0.038)$. Patient-related burnout scores were higher among physician-scientists aged older than 37 years $(\beta=6.25, p=0.002)$ and those who had board certification $(\beta=9.01, p=0.017)$, while these scores were lower among those had larger amounts of funding $(\beta=-5.01, p=0.006)$ or a mentor $(\beta=-5.35, p=0.006)$.
\end{abstract}

Conclusions: Workplace resources and mentorship appear to be associated with lower levels of psychological burnout for both men and women early career physician-scientists.

Keywords: Burnout, Workplace resources, Mentor, Physician-scientist, Grants

\footnotetext{
* Correspondence: knomura@med.akita-u.ac.jp; nomurakyoko@gmail.com

${ }^{2}$ Department of Public Health, Teikyo University School of Medicine, Kaga

2-11-1, Itabashi-ku, Tokyo 173-8605, Japan

${ }^{7}$ Department of Environmental Health Science and Public Health, Akita

University Graduate School of Medicine, 1-1-1 Hondo, Akita 010-8543, Japan

Full list of author information is available at the end of the article
}

(c) The Author(s). 2020 Open Access This article is licensed under a Creative Commons Attribution 4.0 International License, which permits use, sharing, adaptation, distribution and reproduction in any medium or format, as long as you give appropriate credit to the original author(s) and the source, provide a link to the Creative Commons licence, and indicate if changes were made. The images or other third party material in this article are included in the article's Creative Commons licence, unless indicated otherwise in a credit line to the material. If material is not included in the article's Creative Commons licence and your intended use is not permitted by statutory regulation or exceeds the permitted use, you will need to obtain permission directly from the copyright holder. To view a copy of this licence, visit http://creativecommons.org/licenses/by/4.0/ The Creative Commons Public Domain Dedication waiver (http://creativecommons.org/publicdomain/zero/1.0/) applies to the data made available in this article, unless otherwise stated in a credit line to the data. 


\section{Introduction}

Burnout is a pathological syndrome characterized by emotional exhaustion, reduced self-efficacy, and cynicism [1], which is primarily driven by workplace stressors [2]. Physician burnout in particular has reached epidemic proportions globally [3-6], with a prevalence of $43.9 \%$ in a recent national study of physicians in the United States of America [7]. Consequences are negative effects on professionals, patients, organizations, and society [7], including greater tendency towards future sickness, absence, and intention to quit [2].

Physician-scientists see patients and are also engaged in research. Research conducted by physicians is important because those with active clinical practices can directly translate insights from clinical experience to research questions and back into clinical practice, thereby rapidly accelerating the pace and impact of clinical translational research to improve human health $[8$, 9]. Although physician-scientists are a vital segment of the physician workforce, successful academic scientists face many barriers and require attainment of competitive grant funding, adequate research time, mentorship, success in publishing, as well as leadership skills [4, 10]. For example, in Japan with a small number of physicians (2.7 per 1000 population) compared to the average number of 3.3 among all Organisation for Economic Cooperation and Development (OECD) countries [11, 12], physician-scientists are extremely busy with daily clinical practice and have very limited protected time for research. Indeed, contributions to research published in the top general medicine journals from Japan have remained low over the last two decades [13]. Such a unique set of circumstances surrounding highly successful early career physician-scientists may incur tremendous psychological burden and dissatisfaction, resulting in greater intention to leave academia [14, 15].

In this study, we focused on an elite group of early career physician-scientists who are recipients of nationally sponsored, highly competitive research grants and are also actively involved in clinical practice. In a previous study of early- and mid-career physicians in Japan, we found that a research mentor or a Doctor of Medical Science degree is associated with an experience of successfully publishing original papers in peer-reviewed journals, which is both an indication of impact on scholarly discourse and an early indicator for later success [16]. Important challenges in balancing career and family demands for physicians have been demonstrated, particularly for women physicians [5, 17-21]. Much remains to be learned about the nature of challenges and impact of interventions on those pursuing careers in academic medicine [5], especially as there remains controversy about whether performing research is detrimental or protective to overall work-life satisfaction [22, 23].
Prior conceptual frameworks for burnout involve individual, organizational, and job stressors, each contributing to core attributes of burnout (emotional exhaustion, depersonalization, and diminished personal accomplishment) [1]. Hence, the primary purpose of this study was to investigate burnout among physician-scientists, as well as environmental factors (factors external to the self, such as those that are organizational or job-related) which might mitigate aspects of burnout, in order to further inform future organizational policies and practice [24-26]. The secondary purpose of this study is to further elucidate gender differences in burnout experienced by early career physician-scientists $[5,20,21]$.

\section{Methods}

\section{Grant-in-aid for young scientists in Japan}

In this study, we focused on high-achieving physicianscientists who were recipients of the Grant-in-Aid for Young Scientists [27], which are very similar to prestigious K08 and K23 career development awards [28] from the United States National Institutes of Health. These highly competitive awards provide support for supervised research and study to early career clinically trained professionals who have the commitment and potential to develop into productive, independent scientific investigators [29].

\section{Participants}

The authors identified 3143 recipients of the Grant-inAid for Young Scientists from 2014 to 2015 (S, A, or B awards) under the research area of medicine, excluding nursing science and dentistry, using the Kakenhi database (https://kaken.nii.ac.jp/ja/). Among these, we excluded 1353 awardees whose names were not registered in the medical license registration system (https://licenseif.mhlw.go.jp/search/jsp/top.jsp), a database of all medical license holders provided by Japanese Ministry. We then recruited the remaining 1790 awardees to participate by mail, and a total of 490 physician-scientist recipients agreed to participate in this study and returned questionnaires (usable response rate 23.8\%). In total, we excluded 82 survey respondents as they had either withdrawn from the grant (51, with the majority of the reasons for withdrawal identified related to studying or working abroad), did not answer the self-reported question that verified medical licensure (56), or reported no involvement in clinical practice (26) at the time of response. As some of these individuals shared more than one of these exclusion criteria, the total number of eligible subjects left for further analyses was 408 from the original 490 respondents, out of 1713 from the eligible sample as those not seeing patients (77) were excluded from the sample. Therefore, our usable response rate (408/1713) was $23.8 \%$. 
This study was approved by the Teikyo University ethics committee (TU-COI 13-208).

\section{Measures \\ Questionnaire}

The questionnaire had 7 sections including 50 questions in total. Sections consisted of demographic information, physician experience and qualification, working conditions and research activities, organizational factors, mentorship, academic background during medical school, and burnout.

\section{Outcome/dependent variable \\ Copenhagen burnout inventory}

This well-known, publicly available and previously validated inventory examines exhaustion and its attribution on three distinctive facets: personal burnout (general psychological and physical fatigue, 6 items), work-related burnout (7 items), and client-related burnout ("client" is heretofore replaced by "patient" in this study, 6 items) [2]. Each item was answered using a five-point Likert scale scoring: always for 100 , often for 75 , sometimes for 50 , seldom for 25, and never/almost never for 0 . The total score on the scale is the average of the scores on the items (i.e., the total score of each subscale is 100). If fewer than three questions of the personal and patientrelated burnout subscales or if fewer than four questions of the work-related burnout subscale were answered, the respondent was classified as a non-responder. The three burnout subscale scores were calculated with one item reversed in order of response, so that higher overall scores indicated a greater degree of burnout.

\section{Independent variable of interest}

Workplace resources The measure of "Workplace Resources" used in this study was based on a modified version of a checklist for a "female doctor-friendly workplace" that we previously developed using factor analysis [30]. The overall measure in that scale evaluates resources in a wide variety of contexts and seemed relevant for measurement in the context of evaluating initiatives to reduce burnout more generally. Because this original scale was developed primarily for promotion of gender equity among men and women, and was heavily weighted on gender, we conducted an exploratory factor analysis for the purpose of this study to investigate workplace resources for physician-scientists regardless of gender. Promax rotation identified two important factors: "Organizational climate" (Cronbach's alpha coefficient .81) and "Well-being consultation services" (Cronbach's alpha coefficient .74). "Organizational climate" concerns the meaning employees attach to the tangible policies, practices, and procedures they experience in their work situation [31]. It consists of three items-two relating to promotion of gender equity and one relating to career education in the workplace. The questions started with "Does your workplace have" followed by: "an effort to implement strategies to encourage males or the organization to combat gender inequalities?", "seminars and workshops on gender equity for the entire organization?", and "a curriculum on learning career development?". "Well-being consultation services" consists of four items by asking if the workplace has someone or a division for consultation on "career and work", "research", "harassment", and/or "mental health". The response pattern was measured based on the physician-scientist level of agreement on a five-point Likert scale ranging from 'strongly disagree' to 'strongly agree.' Accordingly, "organizational climate" ranges 5-15 points and "well-being consultation services" ranges 5-20 points with higher scores indicating greater degrees of support in the workplace. Among four items which were dropped from the original scale by factor analyses, we retained one item related to the presence of a role model because the main purpose of our study is to investigate burnout and potential mitigating factors in a group of elite early career physicianscientists. We measured this item by asking "Does your workplace have a role model who can keep a good balance of career and personal life?" and the response was divided into a binary: 'agree' vs. either 'disagree' or 'do not know.' Hence, workplace resources in this study consists of three components including organizational climate, well-being consultation services, and a role model with a perceived good balance between work and life. The term workplace resources does not represent a comprehensive summary of the work environment or a comprehensive summary of all of the resources available in the workplace.

\section{Covariates}

The items investigated in this present study included gender, age, years of experience as a physician, Doctor of Medical Science degree, board certification as a specialist, department (surgical, internal medicine, other clinical departments, and public health and basic medicine), amount of funding support, research type (i.e., basic medical science, clinical medicine, social medicine, others), overall weekly working hours and percent time devoted to various activities (patient care, research, education and career, teaching, administration, and others), marital status, household income, and the presence of a mentor (yes versus no or do not know), and workplace resources as defined previously.

\section{Data analyses}

Baseline characteristics of the analytic sample are statistically tested according to gender using a t-test for continuous variables and a chi-square test or a Fisher's exact test for categorical variables. Due to concerns 
about skewed data, analyses for continuous variables were repeated using nonparametric tests. These analyses yielded identical conclusions, so the parametric tests are reported throughout. In order to investigate factors associated with the three dimensions of burnout in the Copenhagen Burnout Inventory, general linear regression models were applied. Because of strong collinearity diagnosed in pre-analyses between age and years of experience as a physician, years of experience was eliminated from the linear regression analyses. We estimated a non-standardized regression coefficient with $95 \%$ confidence interval $(95 \% \mathrm{CI})$, and the standard error for each variable in both univariate and multivariable models. The model selection in multivariable analyses used a forward stepwise method by using "glmselect procedure" in SAS software. We used a stepwise selection because among variables we considered, several variables had collinearity (for example, age and years of experience). For our secondary purpose of investigating gender differences in burnout, we investigated gender associations with burnout as well as any statistical interactions between gender and other covariates.

All analyses were conducted using SAS software Version 9.4 (Cary, NC), with statistical significance set at $p<0.05$.

\section{Results}

Table 1 shows baseline characteristics of the 408 physician-scientists in the analytic sample. Overall, $75 \%$ were male. Mean age was 37 years, and years of experience as a physician was approximately 12 years. Almost $90 \%$ of men were married as compared to $70 \%$ of women $(p<0.0001)$. For research type, a higher proportion of men were engaged in basic medicine or social medicine whereas a higher proportion of women were engaged in clinical medicine $(p=0.024)$. Men were more likely to report longer working hours than women $(62.7$ $\mathrm{h}$ vs. $50.0 \mathrm{~h}$ per week overall, $p<0.001$ ). Distribution of working time also differed by gender; men reported spending more time on education and career $(p=0.022)$ and administrative work $(\mathrm{p}<0.001)$. More than half of women $(63 \%)$ and men $(58 \%)$ answered that they had a mentor, and approximately $10 \%$ of both men and women answered that they do not know if they had a mentor. Among the three types of psychological burnout scores, the personal burnout score was significantly higher in women compared to men (41.9 vs. 36.7 points, difference, 5.2, 95\% CI, 0.5-9.9, $p=0.029)$. Regarding workplace resources, more women than men reported that their workplace had well-being consultation services on "career and work", "research", "harassment", and/or "mental health" $(p=0.004)$. Workplace resources and a role model with a perceived good work-life balance showed no statistically significant differences between women and men.

Table 2 shows factors associated with three types of burnout in univariable linear regression models. Factors that became statistically significant at 0.05 level were female gender for Personal burnout score $(p=0.029)$, and age for Patient-related burnout $(\mathrm{p}=0.004)$, weekly working hour and Work-related burnout $(p=0.037)$, the presence of a mentor (all ps <0.003), more supportive organizational climate (all ps $<0.031$ ), well-being consultation services (all ps $<0.030$ ), and a role model with a good work-life balance (all ps $<0.014$ ).

Table 3 shows factors associated with three types of burnout in stepwise multivariable linear regression models. Personal burnout scores were higher for women $(p=0.045)$ and among physician-scientists who had a mentor $(p=0.010)$ and for those whose workplaces with well-being consultation services $(p=$ 0.022). The work-related burnout score was lower among physician-scientists who had higher amount of grant $(p=0.013)$, a mentor $(p=0.008)$ and whose workplaces had well-being consultation services $(\mathrm{p}=$ $0.008)$ and a role model $(p=0.038)$. Patient-related burnout scores were higher in respondents whose age was older than 37 years $(p=0.002)$ and who had board certification $(p=0.017)$, and was lower among physician-scientists who had higher amount of grant $(p=0.006)$ and had a mentor $(\mathrm{p}=0.006)$.

There were no statistically significant interactions found between gender and any of the other independent variables tested, including presence of a mentor and organizational support factors.

\section{Discussion}

The impact of organizational leadership on physician well-being has recently been explored [32], with organizational factors and interventions found to result in clinically meaningful reductions in burnout $[25,26]$. This study demonstrates that workplace resources and mentorship are associated with lower psychological burnout scores among highly successful early career physician-scientists. The presence of a mentor was associated with lower levels of all three burnout scores while the presence of well-being consultation services was associated with lower personal and work-related burnout scores. Having a role model with a perceived good work-life balance was associated with lower patient-related burnout. Female gender was associated with higher personal burnout scores, but there was no statistically significant interaction between gender and other variables studied, suggesting that mentorship and workplace resources are likely to be important for men and women alike. 
Table 1 Baseline characteristics of the analytic sample (408 Japanese physician-researchers awarded prestigious career development grants)

\begin{tabular}{|c|c|c|c|}
\hline & Female $(n=101)$ & Male $(n=307)$ & $p$ value $^{\mathrm{a}}$ \\
\hline \multicolumn{4}{|l|}{ Individual factor } \\
\hline Age, years & $36.6 \pm 2.5$ & $36.8 \pm 2.7$ & 0.585 \\
\hline Years of experience as a physician & $12.2 \pm 2.5$ & $11.9 \pm 2.7$ & 0.338 \\
\hline Doctor of Medical Science, $n(\%)$ & $77(76.2)$ & $220(71.7)$ & 0.370 \\
\hline Board certified specialist, n (\%) & $89(88.17)$ & $284(92.8)$ & 0.140 \\
\hline Specialty & & & 0.258 \\
\hline Surgical departments & $42(41.6)$ & $116(37.8)$ & \\
\hline Internal Medicine departments & $32(31.7)$ & $124(40.4)$ & \\
\hline Other clinical departments & $9(8.9)$ & $31(10.1)$ & \\
\hline Public Health and Basic Medicine & $18(17.8)$ & $36(11.7)$ & \\
\hline \multicolumn{4}{|l|}{ Grant-in-Aid for Young Scientists } \\
\hline Type B & $97(99.0)$ & $300(98.7)$ & 0.819 \\
\hline Amount of funding support $\times 100$ US\$ & $364(140-741)$ & $377(156-500)$ & 0.149 \\
\hline Research type, n (\%) & & & 0.024 \\
\hline Basic medicine & $41(42.7)$ & $170(55.9)$ & \\
\hline Clinical medicine & $51(53.1)$ & $114(37.5)$ & \\
\hline Social sciences in medicine/others & $4(4.2)$ & $20(6.6)$ & \\
\hline Average weekly working hours & $50.0 \pm 16.7$ & $62.7 \pm 16.7$ & $<0.001$ \\
\hline \multicolumn{4}{|l|}{ Attributes (\%) } \\
\hline Patient care & $59.6 \pm 24.5$ & $54.4 \pm 22.4$ & 0.052 \\
\hline Research & $22.0 \pm 20.2$ & $22.7 \pm 19.2$ & 0.733 \\
\hline Education and Career & $4.5 \pm 3.5$ & $5.5 \pm 4.6$ & 0.022 \\
\hline Teaching & $8.3 \pm 10.2$ & $7.5 \pm 6.5$ & 0.450 \\
\hline Administration & $4.0 \pm 5.2$ & $8.5 \pm 9.9$ & $<0.001$ \\
\hline Others & $4.0 \pm 11.3$ & $3.1 \pm 4.7$ & 0.489 \\
\hline Married, n (\%) & $74(69.8)$ & $293(90.4)$ & $<0.001$ \\
\hline Household income, US\$(1\$=100JPY), n (\%) & & & 0.128 \\
\hline$\geq 200,000$ & $19(19.4)$ & $40(13.1)$ & \\
\hline $150,000-200,000$ & $25(25.5)$ & $80(26.2)$ & \\
\hline $100,000-150,000$ & $36(36.7)$ & $146(47.9)$ & \\
\hline$<100,000$ & $18(18.4)$ & $39(12.8)$ & \\
\hline \multicolumn{4}{|l|}{ Copenhagen Burnout Inventory (0-100 points) ${ }^{\mathrm{b}}$} \\
\hline Personal burnout ( 6 items) & $41.9 \pm 20.5$ & $36.7 \pm 20.8$ & 0.029 \\
\hline Work-related burnout (7 items) & $32.1 \pm 15.3$ & $31.9 \pm 14.8$ & 0.544 \\
\hline Patient-related burnout (6 items) & $28.8 \pm 20.5$ & $27.8 \pm 17.3$ & 0.659 \\
\hline Mentor, $\mathrm{n}(\%)^{c}$ & $64(63.4)$ & $178(58.4)$ & 0.374 \\
\hline \multicolumn{4}{|l|}{ Workplace Resources $^{\mathrm{d}}$} \\
\hline Organizational climate (5-15 points) ${ }^{\mathrm{e}}$ & $7.9 \pm 3.0$ & $8.4 \pm 2.8$ & 0.151 \\
\hline Well-Being consultation services' ${ }^{f}$ (5-20 points) & $14.6 \pm 3.3$ & $13.4 \pm 3.6$ & 0.004 \\
\hline A role model with good work-life balance, $n(\%)^{9}$ & $36(36.0)$ & $127(41.8)$ & 0.307 \\
\hline
\end{tabular}

Values are shown as number of physician-researchers (percentage), or mean \pm S.D. for continuous variables whereas Grants-in-Aid for Young Scientists amount is shown as median (5-95\% confidence intervals). Significance of the difference between male and female: $p$ values were estimated based on a t-test, a chi-square test or a Fisher's exact test ${ }^{a}$

${ }^{\mathrm{b}}$ Each item was answered using a five-point Likert scale scoring: Always for 100 , Often for 75 , Sometimes for 50 , Seldom for 25 , and Never/almost never for 0 . Total score on the scale is the average of the scores on the items (i.e., total score of each subscale is 100). The three burnout facet scores were calculated with one item reversed in order of response, so that higher overall scores indicate higher degree of burnout. 'The mentor item was counted comparing those who have a mentor vs. those who do not have a mentor or those who do not know if they have a mentor. 'Workplace Resources were asked starting with "Does your workplace have the following conditions....?" and response patterns were based on a five point Likert-scale from 'strongly disagree' to 'strongly agree.' eOrganizational climate includes the presence of actions to promote gender equity and presence of career education. 'Well-being consultation services measures if the workplace has an expert or a division for consultation on "career and work", "research", "harassment", and "mental health". " The item measures if the workplace has a role model who can keep a perceived good balance of career and personal life and divided into a binary variable (agree vs. either "do not know" or "disagree" 
Table 2 Factors associated with three types of burnout: univariable models

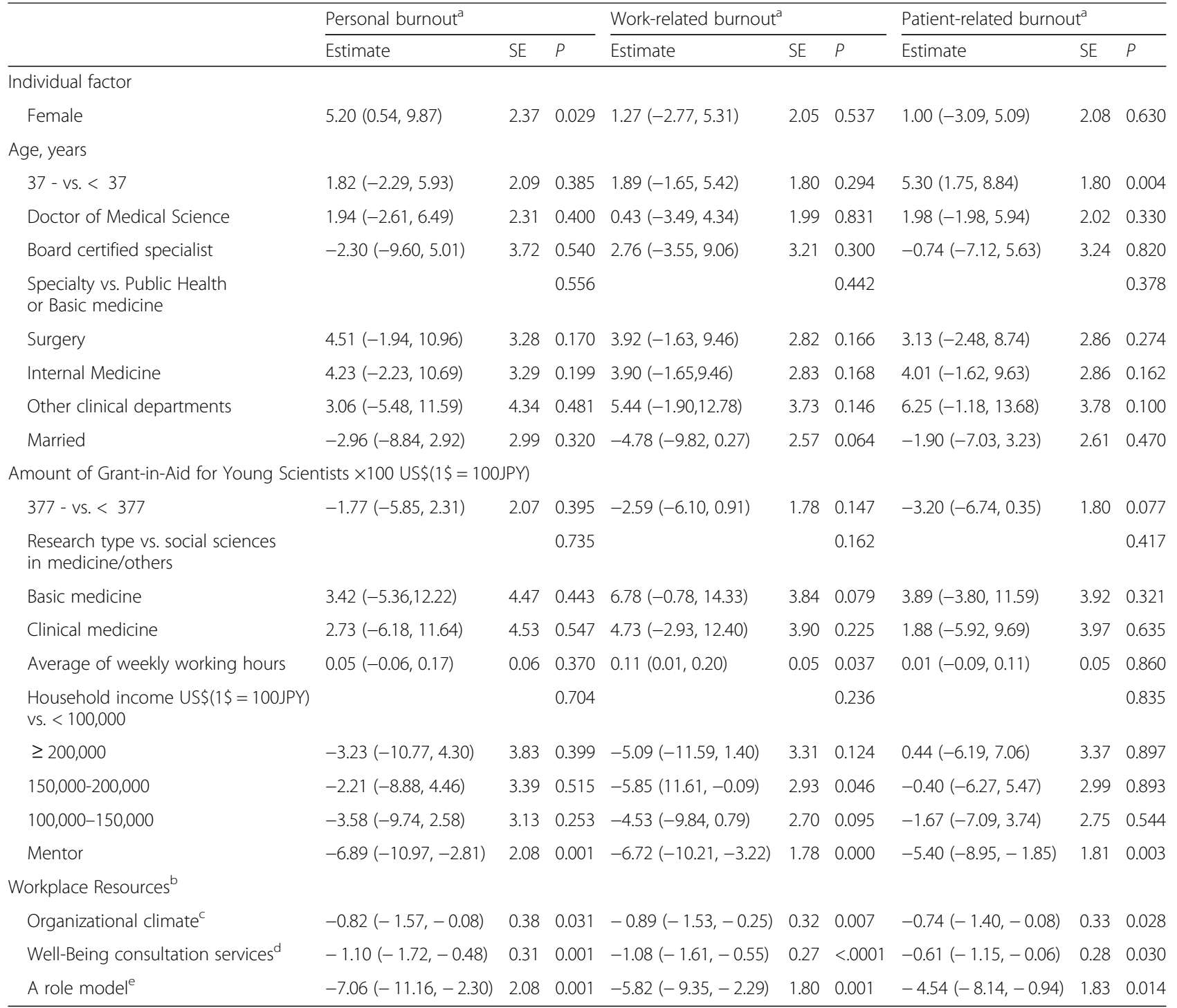

${ }^{a}$ Each item was answered using a five-point Likert scale scoring: Always for 100, Often for 75, Sometimes for 50, Seldom for 25 , and Never/almost never for 0. Total score on the scale is the average of the scores on the items (i.e., total score of each subscale is 100). "Workplace Resources was asked starting with "Does your workplace have the following conditions....?" and response patterns were based on a five point Likert scale from 'strongly disagree' to 'strongly agree.' 'Organizational climate includes the presence of actions to promote gender equity and presence of career education. 'Well-being consultation services measures if the workplace has an expert or a division for consultation on "career and work", "research", "harassment", and/or "mental health". "The item measures if the workplace has a role model who can keep a perceived good balance of career and personal life and divided into a binary variable (agree vs. either "do not know" or "disagree").

Previous meta-analyses [33, 34] have suggested that burnout is a negative psychological response to prolonged stressors and correlates to low work performance and the intention to quit one's job. In this regard, strategies in the workplace that alleviate psychological burden on physician-scientists are vital to retain physicians in both the clinical and academic workforce. Among the components of workplace resources we evaluated, wellbeing consultation services appeared to have a positive association with personal and work-related burnout while the presence of a role model in the workplace who had a perceived good work-life balance was interestingly associated with a lower score of patient-related burnout. A systematic review reported that perceptions of a good organizational climate were significantly associated with positive employee mental health outcomes such as lower levels of burnout, depression, and anxiety [35]. This review specifically highlighted the importance of social support from a supervisor or coworkers in the workplace. The role of social support in the workplace has long been studied by using the job demand-controlsupport model [36]. By contrast, the current study underscores the importance of a generally supportive atmosphere in the workplace. The presence of a mentor in 
Table 3 Factors associated with three types of burnout: multivariable models.

\begin{tabular}{|c|c|c|c|c|c|c|c|c|c|}
\hline & \multicolumn{3}{|c|}{$\begin{array}{l}\text { Personal burnout }{ }^{\mathrm{a}}\left(\mathrm{R}^{2} 8.0 \% n=\right. \\
358 \text { ) }\end{array}$} & \multicolumn{3}{|c|}{$\begin{array}{l}\text { Work-related burnout }{ }^{\mathrm{a}}\left(\mathrm{R}^{2} 11.7 \% n=\right. \\
348 \text { ) }\end{array}$} & \multicolumn{3}{|c|}{$\begin{array}{l}\text { Patient-related burnout }{ }^{\mathrm{a}}\left(\mathrm{R}^{2} 8.5 \%\right. \\
N=349 \text { ) }\end{array}$} \\
\hline & Estimate & SE & $P$ & Estimate & SE & $P$ & Estimate & SE & $P$ \\
\hline \multicolumn{10}{|l|}{ Individual factor } \\
\hline Female & $4.98(0.12,9.84)$ & 2.47 & 0.045 & - & - & - & - & - & - \\
\hline \multicolumn{10}{|l|}{ Age, years } \\
\hline $37-$ vs. $<37$ & - & - & - & - & - & - & $6.25(2.38,10.11)$ & 1.97 & 0.002 \\
\hline Board certified specialist & - & - & - & - & - & - & $9.01(1.60,16.42)$ & 3.77 & 0.017 \\
\hline Married vs. single & - & - & - & $-4.09(-9.37,1.19)$ & 2.69 & 0.129 & - & - & - \\
\hline \multicolumn{10}{|c|}{ Amount of Grant-in-Aid for Young Scientists $\times 100$ US\$(1\$=100JPY $)$} \\
\hline $377-$ vs. $<377$ & $-3.34(-7.57,0.88)$ & 2.15 & 0.120 & $-4.70(-8.38,-1.02)$ & 1.87 & 0.013 & $-5.01(-9.16,-1.55)$ & 1.93 & 0.006 \\
\hline $\begin{array}{l}\text { Research type vs. Social sciences } \\
\text { in medicine /others }\end{array}$ & - & - & - & & & 0.080 & - & - & - \\
\hline Basic medicine & & & & $7.61(-0.20,15.43)$ & 3.97 & 0.056 & & & \\
\hline Clinical medicine & & & & $8.88(1.12,16.64)$ & 3.94 & 0.025 & & & \\
\hline Mentor vs. none & $-5.82(-10.22,-1.42)$ & 2.24 & 0.010 & $-6.12(-9.90,-2.34)$ & 1.92 & 0.002 & $-5.35(-9.16,-1.55)$ & 1.93 & 0.006 \\
\hline \multicolumn{10}{|l|}{ Workplace Resources ${ }^{b}$} \\
\hline Organizational climate ${ }^{c}$ & - & - & - & - & - & - & $-0.54(-1.23,0.14)$ & 0.35 & 0.120 \\
\hline Well-being consultation services ${ }^{d}$ & $-0.79(-1.47,-0.12)$ & 0.34 & 0.022 & $-0.78(-1.36,-0.21)$ & 0.29 & 0.008 & - & - & - \\
\hline A role model ${ }^{e}$ & $-3.82(-8.20,0.57)$ & 2.23 & 0.088 & $-4.00(-7.78,-0.23)$ & 2.08 & 0.038 & $-3.69(-7.67,0.28)$ & 2.02 & 0.068 \\
\hline
\end{tabular}

${ }^{a}$ Each item was answered using a five-point Likert scale scoring: Always for 100 , Often for 75 , Sometimes for 50 , Seldom for 25 , and Never/almost never for 0. Total score on the scale is the average of the scores on the items (i.e., total score of each subscale is 100). ${ }^{b}$ Workplace Resources was asked starting with "Does your workplace have the following conditions....?" and response patterns were based on a five point Likert-scale from 'strongly disagree' to 'strongly agree.' 'Organizational climate includes the presence of actions to promote gender equity and presence of career education. 'Well-being consultation services measures if the workplace has an expert or a division for consultation on "career and work", "research", "harassment", and/or "mental health". "The item measures if the workplace has a role model who can keep a perceived good balance of career and personal life and is divided into a binary variable (agree vs. either "do not know" or "disagree")

the workplace appeared to be a robust, independent factor associated with less psychological burnout. To the extent that effort spent in mentorship is currently not recognized or rewarded at many academic institutions, this finding suggests the importance of finding ways to reward this critical activity. It should be noted that approximately $40 \%$ of our study subjects reported either not having mentor or not knowing if they had a mentor. Another study in Japan that investigated 683 physician-scientists demonstrated that most (91\%) reported that they had a departmental mentor [37]. One explanation of the difference is contextual: as in many other academic institutions around the world, everyone who belongs to academic institutions in Japan has departmental leaders who may serve in a mentorship capacity, but those who indicated having a mentor in the current study are likely to be those with more formal, defined research mentoring relationships due to their attainment of competitive grant awards that support research and career development. Therefore, more emphasis on career development and formal mentor training might be considered, as the association of mentorship with burnout observed in this study might be because mentorship may improve self-efficacy to combat psychological stress and improve retention in academic careers.
Because gender equity issues are prevalent in academia and in medicine, the finding of gender differences in personal burnout scores merit further attention. In Western countries as well, women tend to bear the greater burden of domestic responsibilities [38], be significantly underrepresented in research [39], receive less research funding [35], and appear less frequently than men as authors on research publications [40]. Interestingly, women physicians in the US often have lower salaries than their male counterparts [41], but also provide better hospital care for the elderly [42]. A study of 1066 recipients of $\mathrm{NIH} \mathrm{K}$-awards demonstrated that women were also more likely to experience gender bias and sexual harassment in their careers [43]. In Japan, the situation appears even worse (the gender gap index of Japan ranks at 111th/144 countries in 2016), and the low proportion of women included in this elite sample is evidence of that concern, as is the greater level of personal burnout we observed among women physician-scientists. Just as in many Western studies of similar populations, most participants were married, but women were more likely to be single than men, suggesting that in order to be productive in the workplace (and in particular in academia), women might be more likely to require sacrifice 
in their personal lives with respect to foregoing marriage or delaying child-bearing $[17,44]$. Nevertheless, it is important to emphasize that although burnout scores differed by gender, the positive association between workplace resources and mentorship was observed among men and women alike in this study.

Several limitations in the current work should be addressed. First, because our survey was crosssectional, caution should be employed when making causal inferences. Second, non-response bias may exist if those who chose to respond to our survey differed meaningfully from those who did not. Because this study was conducted as part of a broader research project evaluating gender equity and the support of women, some respondents might have been particularly interested in that topic. Our low usable response rate at $23.8 \%$ makes this sort of response bias a distinct possibility. Third, $75 \%$ of our study participants were men. However, according to a Survey of Physicians, Dentists and Pharmacists conducted by Japanese ministry in 2014, the gender ratio of males to females in physicians is 4:1. Furthermore, recent OECD health data reported that the proportion of women physicians in Japan is the lowest among OECD countries [12]. Hence, although we do not have similar exact statistics for physicianscientists in Japan, we believe the percentage of male respondents $(75 \%)$ in this study closely reflects the actual gender ratio in this population in which men far outnumber women. Fourth, psychological status may vary according to events associated not only with work but also in one's personal life, and the current study did not include measures of experiences such as the presence of children or caregiving for elderly parents. Fifth, it is possible that some other underlying confounding factor leads to the observed associations. For example, although the clinical department was not significant in our study, the department discipline and resources might be potentially associated. Indeed, R-squared statistics ranged from 7.1 to $13.4 \%$, indicating that only approximately $10 \%$ of the dependent variable was explained by the independent variables in the models. Careful interpretation of our results is therefore required, and a detailed understanding of the underlying sociodemographic characteristics and workplace environment (which was not thoroughly measured in our study) represents a step forward in this regard.

\section{Conclusion}

In their efforts to mitigate burnout and help early career men and women physician-scientists achieve their full potential, academic medical centers might consider incorporating workplace resources and formal mentoring programs in their institutional policies. In the US, the Accreditation Council for Graduate Medical Education has recently required programs to promote wellness and monitor burnout among postgraduate medical trainees [45]. Similar types of policies might be useful for early career physician-scientists in Japan. Gender differences in personal burnout merit further attention as developing and maintaining a resilient physician scientist workforce is vital to providing both high quality health care and translating research innovations to the bedside.

\section{Acknowledgements}

We thank all of the participants in our study.

\section{Authors' contributions}

KN had the original idea for the study, developed in collaboration with RJ. $\mathrm{KN}$ and ST prepared the ethical application and the list of the questionnaires, with support from RK, HH and HO. KN, ST, AT, RK, HH and HO collected the data. KN and AT carried out preliminary data analysis. KN drafted the paper, with CP providing critical revisions and substantial writing and ST, AT, RK, $\mathrm{HH}, \mathrm{HO}$ and $\mathrm{RJ}$ contributing to later drafts. All authors critically reviewed the final paper before submission. The author(s) read and approved the final manuscript.

\section{Funding}

KN received a research grant funded by the Ministry of Health, Labor, and Welfare of Japan (Grant in Scientific Research C, Number 25460814 and B, Number 16H0526.). CP reports grants from the United States National Institutes of Health and the University of Michigan Office of Research outside the submitted work. RJ reported grants from the United States National Institutes of Health, National Cancer Institute, Doris Duke Foundation, Komen Foundation, Greenwall Foundation, Genentech, and Blue Cross Blue Shield of Michigan; personal fees from Amgen and Vizient; and stock options from Equity Quotient outside the submitted work. No other disclosures were reported.

\section{Availability of data and materials}

The datasets generated and/or analyzed during the current study are not publicly available due to protecting the privacy of participants but are available in anonymized format from the corresponding author upon reasonable request.

\section{Ethics approval and consent to participate}

This study was approved by the Teikyo University ethics committee (TU-COI 13-208).

\section{Consent for publication}

Not applicable.

\section{Competing interests}

None.

\footnotetext{
Author details

${ }^{1}$ Center for Bioethics and Social Sciences in Medicine, University of Michigan Medical School, Ann Arbor, MI, USA. 'Department of Public Health, Teikyo University School of Medicine, Kaga 2-11-1, Itabashi-ku, Tokyo 173-8605, Japan. ${ }^{3}$ Department of Preventive Medicine and Public Health, Keio University School of Medicine, Shinanomachi 35, Shinjuku-ku, Tokyo 160-8582, Japan. ${ }^{4}$ Department of Obstetrics and Gynecology, Teikyo University School of Medicine, Kaga 2-11-1, Itabashi-ku, Tokyo 173-8605, Japan. ${ }^{5}$ Support Center for women physicians and researchers, Kaga 2-11-1, Itabashi-ku, Tokyo 173-8605, Japan. ${ }^{6}$ Department of Radiation Oncology and Center for Bioethics and Social Sciences in Medicine, University of Michigan, Ann Arbor, MI, USA. 'Department of Environmental Health Science and Public Health, Akita University Graduate School of Medicine, 1-1-1 Hondo, Akita 010-8543, Japan.
} 


\section{Received: 6 February 2019 Accepted: 11 May 2020}

Published online: 03 June 2020

\section{References}

1. Schaufeli W. Christina Maslach: professional burnout: recent developments in theory and research. Washington DC: Taylor \& Francis; 1993.

2. Kristensen MB TS, Villadsen E, Christensen KB. The Copenhagen burnout inventory: a new tool for the assessment of burnout. Work Stress. 2005;19: 192-207.

3. Shanafelt TD, Boone S, Tan L, Dyrbye LN, Sotile W, Satele D, West CP, Sloan J, Oreskovich MR. Burnout and satisfaction with work-life balance among US physicians relative to the general US population. Arch Intern Med. 2012;172: 1377-85.

4. Holleman WL, Cofta-Woerpel LM, Gritz ER. Stress and morale of academic biomedical scientists. Acad Med. 2015;90:562-4.

5. Perumalswami $C R$, Griffith $K A$, Jones $R D$, Stewart A, Ubel PA, Jagsi $R$. Patterns of work-related burnout in physician-scientists receiving career development awards from the National Institutes of Health. JAMA Int Med. 2019;e194317. https://doi.org/10.1001/jamainternmed.2019.4317.

6. Soler JK, Yaman H, Esteva M, Dobbs F, Asenova RS, Katic M, Ozvacic Z Desgranges JP, Moreau A, Lionis C, et al. Burnout in European family doctors: the EGPRN study. Fam Pract. 2008;25:245-65.

7. Shanafelt TD, West CP, Sinsky C, Trockel M, Tutty M, Satele DV, Carlasare LE, Dyrbye LN. Changes in burnout and satisfaction with work-life integration in physicians and the general US working population between 2011 and 2017. Mayo Clin Proc. 2019;94:1681-94.

8. Yin HL, Gabrilove J, Jackson R, Sweeney C, Fair AM, Toto R. Sustaining the clinical and translational research workforce: training and empowering the next generation of investigators. Acad Med. 2015;90: $861-5$.

9. Day $\mathrm{C}$. The changing funding environment for clinical academics. Lancet. 2016;387:S3-5.

10. Jagsi $R$, Griffith $K A$, Jones $R D$, Stewart $A$, Ubel PA. Factors associated with success of clinician-researchers receiving career development awards from the National Institutes of Health: a longitudinal cohort study. Acad Med. 2017:92:1429-39.

11. Ministry of Internal Affairs and Communications: Vital Statistics. In Survey of Physicians, Dentists and Pharmacists 2014. http://www.mhlw.go.jp/toukei/ saikin/hw/ishi/14/dl/kekka_1.pdf. Accessed 17 Nov 2017.

12. OECD Health Statistics: health at a Glance: OECD indicators. 2015. http:// stats.oecd.org/index.aspx? DataSetCode=HEALTH_STAT\#. Accessed 17 Nov 2017.

13. Fukui T, Takahashi O, Rahman M. Japanese representation in leading general medicine and basic science journals: a comparison of two decades. Tohoku J Exp Med. 2013;231:187-91.

14. Landon BE, Reschovsky JD, Pham HH, Blumenthal D. Leaving medicine: the consequences of physician dissatisfaction. Med Care. 2006:44:234-42.

15. Lacy BE, Chan JL. Physician burnout: the hidden health care crisis. Clin Gastroenterol Hepatol. 2018;16:311-7.

16. Takenoshita S, Nomura K, Ohde S, Deshpande GA, Sakamoto H, Yoshida H, Urayama K, Bito S, Ishida Y, Shimbo T, et al. Having a Mentor or a doctoral degree is helpful for mid-career physicians to publish papers in peer-reviewed journals. Tohoku J Exp Med. 2016; 239:325-31.

17. Nomura K, Yamazaki Y, Gruppen LD, Horie S, Takeuchi M, Illing J. The difficulty of professional continuation among female doctors in Japan: a qualitative study of alumnae of 13 medical schools in Japan. BMJ Open. 2015;5:e005845.

18. Jolly S, Griffith KA, DeCastro R, Stewart A, Ubel P, Jagsi R. Gender differences in time spent on parenting and domestic responsibilities by high-achieving young physician-researchers. Ann Intern Med. 2014;160:344-53.

19. Keeton K, Fenner DE, Johnson TR, Hayward RA. Predictors of physician career satisfaction, work-life balance, and burnout. Obstet Gynecol. 2007;109:949-55.

20. Templeton KC, Bernstein J, Sukhera LM, Nora C, Newman H, Burstin C, Guille LL, Schwarze ML, Sen S, Busis N. Gender-based differences in burnout: issues faced by women physicians. NAM Perspectives. Washington, DC: Discussion Paper, National Academy of Medicine; 2019. https://doi.org/10. 31478/201905a.

21. Takeuchi M, Nomura K, Horie S, Okinaga H, Perumalswami CR, Jagsi R. Direct and indirect harassment experiences and burnout among academic faculty in Japan. Tohoku J Exp Med. 2018;245(1):37-44.
22. Pololi LH, Krupat E, Civian JT, Ash AS, Brennan RT. Why are a quarter of faculty considering leaving academic medicine? A study of their perceptions of institutional culture and intentions to leave at 26 representative U.S. medical schools. Acad Med. 2012;87:859-69.

23. Shanafelt TD, West CP, Sloan JA, Novotny PJ, Poland GA, Menaker R, Rummans TA, Dyrbye LN. Career fit and burnout among academic faculty. Arch Intern Med. 2009;169:990-5.

24. West CP, Dyrbye LN, Erwin PJ, Shanafelt TD. Interventions to prevent and reduce physician burnout: a systematic review and meta-analysis. Lancet. 2016;388:2272-81.

25. Panagioti M, Panagopoulou E, Bower P, Lewith G, Kontopantelis E, ChewGraham C, Dawson S, van Marwijk H, Geraghty K, Esmail A. Controlled interventions to reduce burnout in physicians: a systematic review and meta-analysis. JAMA Intern Med. 2017;177:195-205

26. Taka F, Nomura K, Horie S, Takemoto K, Takeuchi M, Takenoshita S, Murakami A, Hiraike H, Okinaga H, Smith DR. Organizational climate with gender equity and burnout among university academics in Japan. Ind Health. 2016:54:480-7.

27. Japan Society for the Promotion of Science. Types of Grants Programs Available at: https://www.jsps.go.jp/english/e-grants/grants01.html. Accessed 2017 Nov 17.

28. National Institute of General Medical Sciences. Mentored Career Development Awards (K08, K23, K25, K99/R00). https://www.nigms.nih.gov/ training/careerdev/Pages/default.aspx. Accessed 17 Nov 2017.

29. Finney JW, Amundson EO, Bi X, Cucciare MA, Eisen SA, Finlay AK, Halvorson MA, Hayashi K, Owens DK, Maisel NC, et al. Evaluating the productivity of VA, NIH, and AHRQ health services research career development awardees. Acad Med. 2016:91:563-9.

30. Horie S, Takeuchi M, Yamaoka K, Nohara M, Hasunuma N, Okinaga H, Nomura K. Checklist development for women-doctor-friendly working conditions in a hospital setting. Nihon Eiseigaku Zasshi. 2015;70:264-70.

31. Schneider B, Ehrhart MG, Macey WH. Organizational climate and culture. Annu Rev Psychol. 2013:64:361-88.

32. Shanafelt TD, Gorringe G, Menaker R, Storz KA, Reeves D, Buskirk SJ, Sloan JA, Swensen SJ. Impact of organizational leadership on physician burnout and satisfaction. Mayo Clin Proc. 2015;90:432-40.

33. Robbins JM, Ford MT, Tetrick LE. Perceived unfairness and employee health a meta-analytic integration. J Appl Psychol. 2012;97:235-72.

34. Colquitt JA, Conlon DE, Wesson MJ, Porter CO, Ng KY. Justice at the millennium: a meta-analytic review of 25 years of organizational justice research. J Appl Psychol. 2001;86:425-45.

35. Bronkhorst B, Tummers L, Steijn B, Vijverberg D. Organizational climate and employee mental health outcomes: a systematic review of studies in health care organizations. Health Care Manag Rev. 2015;40:254-71.

36. Karasek R, Theorell T. Healthy work: stress, productivity and the the reconstruction of working life: basic books; 1990

37. Sakushima K, Mishina H, Fukuhara S, Sada K, Koizumi J, Sugioka T, Kobayashi N, Nishimura M, Mori J, Makino H, Feldman MD. Mentoring the next generation of physician-scientists in Japan: a cross-sectional survey of mentees in six academic medical centers. BMC Med Educ. 2015;15:54.

38. Jagsi R, Motomura AR, Griffith KA, Rangarajan S, Ubel PA. Sex differences in attainment of independent funding by career development awardees. Ann Intern Med. 2009:151:804-11.

39. Jagsi R, Guancial EA, Worobey CC, Henault LE, Chang Y, Starr R, Tarbell NJ, Hylek EM. The "gender gap" in authorship of academic medical literature--a 35-year perspective. N Engl J Med. 2006;355:281-7.

40. Diamond SJ, Thomas CR Jr, Desai S, Holliday EB, Jagsi R, Schmitt C, Enestvedt BK. Gender differences in publication productivity, academic rank and career duration among U.S. academic gastroenterology faculty. Acad Med. 2016:91:1158-63.

41. Jagsi R, Griffith KA, Stewart A, Sambuco D, DeCastro R, Ubel PA. Gender differences in the salaries of physician researchers. JAMA. 2012;307:2410-7.

42. Tsugawa $Y$, Jena AB, Figueroa JF, Orav EJ, Blumenthal DM, Jha AK Comparison of hospital mortality and readmission rates for Medicare patients treated by male vs female physicians. JAMA Intern Med. 2017; 177:206-13.

43. Jagsi $R$, Griffith $K A$, Jones $R$, Perumalswami $C R$, Ubel $P$, Stewart A. Sexual harassment and discrimination experiences of academic medical faculty. JAMA. 2016;315:2120-1. 
44. Stentz NC, Griffith KA, Perkins E, Jones RD, Jagsi R. Fertility and childbearing among American female physicians. J Women's Health (Larchmt). 2016;25: 1059-65.

45. Wallace JE, Lemaire JB, Ghali WA. Physician wellness: a missing quality indicator. Lancet. 2009;374:1714-21.

\section{Publisher's Note}

Springer Nature remains neutral with regard to jurisdictional claims in published maps and institutional affiliations.

Ready to submit your research? Choose BMC and benefit from:

- fast, convenient online submission

- thorough peer review by experienced researchers in your field

- rapid publication on acceptance

- support for research data, including large and complex data types

- gold Open Access which fosters wider collaboration and increased citations

- maximum visibility for your research: over $100 \mathrm{M}$ website views per year

At $\mathrm{BMC}$, research is always in progress.

Learn more biomedcentral.com/submissions 